\title{
REVIEWS
}

\section{Should we establish chest pain observation units in the UK? A systematic review and critical appraisal of the literature}

\author{
Steve W Goodacre
}

\begin{abstract}
Objectives-The chest pain observation unit (CPOU) has been developed in the United States to allow rigorous assessment of patients presenting with chest pain, thus expediting their discharge if assessment is negative. This review aims to examine the evidence for effectiveness and economic efficiency of the CPOU and to explore whether data from the United States can be extrapolated to the UK.

Method-Search of the literature using Medline and critical appraisal of the validity of the data.

Results-Five studies comparing outcomes of CPOU care with routine practice showed no significant difference in objective measures including mortality or missed pathology. Eleven studies described outcomes of a cohort of CPOU patients. Follow up was comprehensive and demonstrated no clinically significant evidence of missed pathology. Nine studies comparing CPOU costs with routine care demonstrated impressive cost savings that were more modest when randomised comparisons were made.

Conclusion-CPOU care is safe and costs are well defined. There is no strong evidence that a CPOU will improve outcomes if routine practice is good. Cost savings have been shown when compared with routine care in the United States but may not be reproduced the UK.

(F Accid Emerg Med 2000;17:1-6)
\end{abstract}

Keywords: chest pain; observation unit; myocardial infarction

Accident and

Emergency

Department, Northern

General Hospital,

Herries Road,

Sheffield S5 7AU

Correspondence to:

Dr Goodacre, Research

Fellow in Accident and

Emergency (e-mail-

steveg@doctors.org.uk)

Accepted 14 September 1999
During the 1980s studies from the United States suggested that approximately $3 \%-4 \%$ of patients attending hospital with acute myocardial infarction (AMI) were discharged from the emergency department, ${ }^{12}$ and many of those admitted ultimately had a benign cause. ${ }^{34} \mathrm{~A}$ similar study from the UK found that $11.8 \%$ of patients presenting to the accident and emergency (A\&E) department with acute ischaemic heart disease were discharged home, ${ }^{5}$ and audit of attendances with chest pain have found that many are discharged by junior staff without recourse to second opinion, ${ }^{6}$ and errors of electrocardiogram (ECG) interpretation are frequent. ${ }^{5} 7$

One approach to this problem has been the development of the chest pain observation unit (CPOU) ${ }^{8}{ }^{8}$ Patients presenting with chest pain who are at low risk of AMI undergo a short period of rigorous monitoring with serial ECGs and cardiac enzymes before receiving some form of provocative testing, usually exercise treadmill. If all tests are negative they can be discharged home.

It is now estimated that $22 \%$ of emergency departments in the United States have a $\mathrm{CPOU}^{10}$ and interest is growing in the UK. ${ }^{11}$

The rationale for their development is both clinical and economic. Rigorous evaluation is intended to increase diagnostic certainty and prevent inadvertent discharge of patients with AMI or unstable angina, while reducing length of stay should reduce costs. In addition, the very high legal cost in the United States of discharging a patient with unrecognised AMI has been a driving force there, which has yet to fully evolve in the UK.

To be considered effective a CPOU must be demonstrated to improve, or at least match, patient outcomes for normal practice. The outcomes usually measured are: mortality, "missed AMI", reattendance, complications, cardiovascular procedures, and final diagnoses. Mortality is the most objective outcome measure but is fortunately rare. There is little scope for the CPOU to improve this outcome, while increased mortality is a very insensitive measure of CPOU safety.

The purpose of a CPOU is to rule out AMI and detect critical myocardial ischaemia. The latter may be hard to define by objective diagnostic criteria, but the missed AMI rate (the proportion of cases of AMI attending the emergency department who are inadvertently discharged) is an important indicator of effectiveness. However the accuracy of this measurement will depend upon the rigour with which it pursued. The estimates of missed AMI rate quoted above involved reassessment of discharged patients with ECG and enzyme testing at 48-72 hours after discharge. ${ }^{12}$ Unless those discharged from a CPOU are followed up with equal rigour, estimates of the 
missed AMI rate should be considered with caution. The other outcome measures are related to processes of care rather than definitive outcomes. As such their relationship to patient benefit will require interpretation.

Economic evaluation depends upon the evidence of effectiveness. It is anticipated that CPOU outcomes will either match or improve upon routine care and costs will be lower. If this is true then the CPOU is dominant over routine care and there is no need to determine any cost effectiveness ratio. However, claims of cost saving should be scrutinised with the same rigour as claims of effectiveness. In particular, the differences in health service costs and clinical practice that exist between countries mean that cost savings may not be reproduced elsewhere.

The aim of this review is to examine the evidence for both the effectiveness and the economic efficiency of the CPOU and to explore whether data from the US can be extrapolated to the UK.

\section{Method}

A computerised search of the literature was undertaken using Medline. Articles were searched for the textwords "chest pain observation", "chest pain evaluation", or "chest pain assessment". The medical subheading (MeSH term) "chest pain" was also searched in combination with $\mathrm{MeSH}$ terms: "emergencies", "observation", "myocardial ischaemia", "unstable angina", and "myocardial infarction (diagnosis)". Any article that reported costs or outcomes for patients managed on a CPOU was reviewed. The bibliography of each article was searched for related citations. Articles relating to chest pain clinics ${ }^{12}{ }^{13}$ (rapid access outpatient cardiology services) were not included. Although similar, these services have a different source of referral and tackle a different clinical problem to the CPOU.

The question of effectiveness was addressed in two ways. Firstly studies were selected that compared outcomes of CPOU management with those of routine patient care. The quality of these studies was assessed against standard criteria covering reporting, statistical analysis, internal validity (bias and confounding), and external validity (generalisability). ${ }^{14}{ }^{15}$ Particu- lar attention was directed at determining how subjects were selected and allocated to intervention (CPOU) and control (routine care) groups, how the controls were chosen, how follow up was performed for each group, the completeness of follow up, and the range of outcomes examined.

Secondly, studies were selected that made no comparison but simply described outcomes of CPOU patients. Quality was assessed by determining how subjects were selected, the nature and completeness of follow up, and the range of outcomes examined. Although descriptive studies cannot demonstrate effectiveness on their own, they may be helpful in adding to a body of knowledge that a technology can be safely applied in a variety of settings.

To address the economic question studies were selected that compared CPOU costs with those of a comparison group. Criteria relating to the reporting of economic evaluations have recently been published. ${ }^{16}$ Unfortunately most of the literature relating to CPOUs were submitted for publication before this and the reports of economic data are, by comparison, poor. Hence rigorous examination of quality is not possible. Quality assessment was therefore focused upon essential criteria for internal and external validity of the economic comparison, such as the method of allocation to intervention and control groups, the choice of controls, the range of costs included and the costing technique used. As most of the data obtained was observational and nonrandomised, no attempt to perform a metaanalysis was made. Instead the various estimates of costs were examined for heterogeneity and explanations for any differences sought.

\section{Results}

All the studies found were from the United States. Six studies compared outcomes for patients admitted to a CPOU to a control group. ${ }^{17-22}$ One of these, which compared outcomes principally in terms of patient satisfaction, ${ }^{22}$ ran alongside a randomised trial of cost effectiveness ${ }^{18}$ and will be discussed separately. The results of the five remaining studies are summarised in table 1 .

Table 1 Comparative studies of chest pain observation units (CPOUs)

\begin{tabular}{|c|c|c|c|c|}
\hline First author & Subjects & $\begin{array}{l}\text { Allocation to } \\
\text { treatment }\end{array}$ & Controls & Outcomes \\
\hline Farkouh $^{17}$ & $\begin{array}{l}\text { Intermediate risk of } \\
\text { myocardial ischaemia }\end{array}$ & Randomised & $\begin{array}{l}\text { "Usual care": monitored } \\
\text { cardiology bed }\end{array}$ & $\begin{array}{l}\text { No significant difference for in-hospital, } 30 \text { day } \\
\text { or } 6 \text { month event rate. No significant } \\
\text { difference for return visits }\end{array}$ \\
\hline Roberts $^{18}$ & $\begin{array}{l}\text { Low risk of } \mathrm{MI}(<7 \%) \text { but } \\
\text { admission planned }\end{array}$ & Randomised & Inpatient telemetry unit & $\begin{array}{l}\text { At } 8 \text { weeks: no deaths, no significant difference } \\
\text { in rehospitalization }(6.1 \% v 4.5 \%) \text {, fewer } \\
\text { indeterminate diagnoses in CPOU group } \\
(13 \% v 45 \%)\end{array}$ \\
\hline Gomez $z^{\star 19}$ & $\begin{array}{l}\text { Low risk of } \mathrm{MI}(<7 \%) \text { but } \\
\text { admission planned }\end{array}$ & Randomised & Routine care: hospital admission & $\begin{array}{l}\text { No death, MI or coronary artery disease in } \\
\text { either group at } 30 / 7.6 \% \text { of CPOU group } \\
\text { re-presented, } 7 \% \text { of admitted group required } \\
\text { further investigation }\end{array}$ \\
\hline Gaspoz $^{20}$ & $\begin{array}{l}\text { Low risk of MI with anticipated } \\
\text { stay }<48 \text { hours }\end{array}$ & Non-randomised & $\begin{array}{l}\text { Contemporaneous, eligible for } \\
\text { CPOU but either discharged or } \\
\text { admitted to hospital }\end{array}$ & $\begin{array}{l}\text { No significant difference in complications, MI } \\
\text { or death at } 72 \text { hours or } 6 \text { months }\end{array}$ \\
\hline Kerns $^{21}$ & $\begin{array}{l}\text { Atypical chest pain, low risk of } \\
\text { ischaemia }\end{array}$ & Non-randomised & $\begin{array}{l}\text { Contemporaneous, eligible for } \\
\text { CPOU but admitted to hospital }\end{array}$ & $\begin{array}{l}\text { No death, MI or coronary artery disease at } \\
3 \text { or } 6 \text { months in either group }\end{array}$ \\
\hline
\end{tabular}

${ }^{\star}$ Compared costs with both randomised and historical controls but only randomised controls had outcome data collected. 
Table 2 Descriptive studies of cohorts of chest pain observation unit patients

\begin{tabular}{|c|c|c|c|c|c|c|}
\hline First author & No & $\begin{array}{l}\% \\
\text { Discharged } \\
\text { from } C P O U\end{array}$ & Type of follow up & $\begin{array}{l}\text { Timing of } \\
\text { follow up }\end{array}$ & $\%$ Followed up & Adverse events detected \\
\hline Farkouh $^{17}$ & 212 & 46 & Outpatient review & $\begin{array}{l}72 \text { hour } \\
30 \text { day } \\
6 \text { month }\end{array}$ & 99 & $\begin{array}{l}\text { In hospital: } 5 \mathrm{MI}, 1 \mathrm{CCF}, 1 \text { death } \\
30 \text { day: } 1 \text { death } \\
6 \text { month: } 2 \mathrm{MI}, 3 \mathrm{CCF}, 1 \text { death }\end{array}$ \\
\hline Roberts $^{18}$ & 82 & 55 & Inpatient, telephone, clinic, or HIS* & $\begin{array}{l}24 \text { hour } \\
8 \text { weeks }\end{array}$ & $\begin{array}{l}100 \\
85 \\
96\end{array}$ & $\begin{array}{l}\text { No deaths } \\
6.1 \% \text { rehospitalised }\end{array}$ \\
\hline Gomez $^{19}$ & 50 & 82 & Telephone, mail or clinic & 30 day & 98 & $\begin{array}{l}\text { No death, } \mathrm{MI} \text {, or coronary artery disease } \\
6 \% \text { represented }\end{array}$ \\
\hline Gaspoz $^{20}$ & 592 & 84 & Telephone, record review, or BVS $\dagger$ & $\begin{array}{l}72 \text { hour } \\
6 \text { month }\end{array}$ & $\begin{array}{l}98 \\
100 \dagger\end{array}$ & $\begin{array}{l}5 \mathrm{MI} \text { within } 72 \text { hours of discharge } \\
10 \mathrm{MI} \text { and } 13 \text { deaths ( } 10 \text { cardiac related) within } 6 \text { months }\end{array}$ \\
\hline Kerns $^{21}$ & 32 & 100 & Telephone questionnaire & $\begin{array}{l}3 \text { month } \\
6 \text { month }\end{array}$ & Not reported & No death, MI, or coronary artery disease \\
\hline Gibler $^{23}$ & 1010 & 82 & $\begin{array}{l}\text { Telephone, mail, clinic, or death } \\
\text { records }\end{array}$ & 30 day & Not reported & $\begin{array}{l}1 \text { return with } \mathrm{MI} \text { at } 3 \text { days } \\
5 \text { deaths ( } 1 \text { admitted with } \mathrm{MI}, 1 \text { unknown cause, and } 3 \text { non- } \\
\text { cardiac causes) }\end{array}$ \\
\hline $\operatorname{Kirk}^{24}$ & 212 & 87 & $\begin{array}{l}\text { Telephone, mail, hospital, or death } \\
\text { records }\end{array}$ & 30 day & 94 & No morbidity or mortality \\
\hline Graff $^{25}$ & 6005 & 76 & Evidence of reattendance & 72 hour & $\begin{array}{l}\text { No formal } \\
\text { follow up }\end{array}$ & 3 returns with $\mathrm{MI}$ within 72 hours \\
\hline Mikhail $^{26}$ & 502 & 86 & Telephone questionnaire & $\begin{array}{l}3 \text { or } 14 \text { day } \\
150 \text { day }\end{array}$ & 94 & $\begin{array}{l}2 \text { deaths at } 2 \text { weeks and } 2 \text { months } \\
1 \text { MI } \\
7 \text { PTCA or CABG }\end{array}$ \\
\hline Stomel ${ }^{28}$ & 473 & 96 & Telephone or record review & 12 month & 93 & 7 unstable angina on medical treatment, 3 CABG, 1 PTCA \\
\hline De Leon ${ }^{27}$ & 495 & 66 & Telephone or mail & Not stated & 69 & No morbidity or mortality detected in discharged patients \\
\hline
\end{tabular}

*Hospital information system: records if patient is alive or dead.

†BVS is the Bureau of Vital Statistics: records if patient is alive or dead. CABG = coronary artery bypass graft; $\mathrm{CCF}=\mathrm{congestive} \mathrm{cardiac} \mathrm{failure;} \mathrm{MI}=\mathrm{myocardial}$ infarction; PTCA $=$ percutaneous transluminal coronary angioplasty.

Reporting was adequate for all studies. The objectives, interventions, outcomes, main findings, and patient characteristics were well described. All studies included appropriate statistical analysis except that of Kerns et al. ${ }^{21}$ Regarding validity, blinding of patients and carers was inevitably absent from all the studies and represents a potential source of bias. Three trials were randomised and are therefore the most likely to be valid. ${ }^{17-19}$ The nonrandomised study by Gaspoz et al made appropriate adjustment for confounding, ${ }^{20}$ but only random allocation can take into account the influence of unknown confounders. No such adjustment was made by Kerns et al and taking into account the small number and lack of statistical analysis, ${ }^{21}$ this study can only be considered to represent pilot data. Only the study by Farkouh et al described the full details of patients excluded from the trial. ${ }^{17}$ Without such details it is impossible to determine whether the trial population is representative of all low risk patients with chest pain and we must be cautious about applying findings to other patient groups.

The AMI rate in the study groups varied from zero to $4.9 \%$ and did not differ significantly between CPOU and control groups in any study. Baseline characteristics, in terms of age, sex, type of pain, risk factors, and history of coronary artery disease, did not differ significantly between CPOU and control groups in any of the randomised trials. ${ }^{17-19}$ In the study by Gaspoz et al the control patients were significantly more likely to be male, have recurrent or atypical pain, have abnormal ECGs, and have a history of ischaemic heart disease. ${ }^{20}$ No statistical analysis of baseline characteristics was carried out by Kerns et al. ${ }^{21}$

Six studies were found that described outcomes for CPOU subjects without comparison with a control group, ${ }^{23-25}$ or used a control group for cost analysis only. ${ }^{26-28}$ Hence there were a total of 11 studies reporting follow up of a cohort of CPOU patients. These are outlined in table 2. All studies excluded subjects with an ischaemic ECG and selected those at low risk of AMI. Often this selection involved a subjective element of physician judgment. Most studies achieved high follow up rates. ${ }^{17-20} 242628$ This follow up was typically done by mail or telephone and was therefore adequate to exclude major morbidity but not "missed AMI" by the criteria outlined above.

Table 3 Estimates of cost savings per patient managed on a chest pain observation unit

\begin{tabular}{|c|c|c|c|c|c|}
\hline First author & $\begin{array}{l}\text { Cost saving } \\
\text { per patient }\end{array}$ & $\begin{array}{l}\text { Randomised, } \\
\text { contemporaneous, or } \\
\text { historical controls }\end{array}$ & $\begin{array}{l}\text { Controls admitted } \\
\text { or discharged }\end{array}$ & Time period costed & Costing technique \\
\hline Kerns $^{21}$ & $\$ 1873^{\star}$ & Contemporaneous & All admitted & In-hospital only & Patient charges \\
\hline \multirow[t]{2}{*}{ Hoekstra $^{29}$} & $\$ 1160^{\star}$ & Contemporaneous & All admitted & In-hospital only & Patient charges (excluding physician charges) \\
\hline & $\$ 2030^{\star}$ & Contemporaneous & All admitted & In-hospital only & Patient charges (excluding physician charges) \\
\hline Rodriguez $^{30}$ & $\$ 1564^{\star}$ & Contemporaneous & All admitted & In-hospital only & Mean hospital charge \\
\hline Stomel $^{28}$ & $\$ 1497$ & Contemporaneous & All admitted & In-hospital only & Hospital financial data system costing \\
\hline Mikhail $^{26}$ & $\$ 1470^{\star}$ & Historical & All admitted & In-hospital only & Hospital financial data system costing \\
\hline Sayre $^{31}$ & $\$ 1449^{\star}$ & Contemporaneous & All admitted & In-hospital only & Engineered standards \\
\hline \multirow[t]{2}{*}{ Gomez $^{19}$} & $\$ 1165+$ & Historical & All admitted & In-hospital +30 day follow up & Charges incurred on patients itemised account \\
\hline & $\$ 624 \dagger$ & Randomised & All admitted & In-hospital only & Charges incurred on patients itemised account \\
\hline Gaspoz $^{20}$ & $\$ 698^{\star}$ & Contemporaneous & Admitted + discharged & In-hospital +6 month follow up & Detailed costing procedure \\
\hline Roberts $^{18}$ & $\$ 567^{\star}$ & Randomised & All admitted & In-hospital only & Detailed costing procedure \\
\hline
\end{tabular}

${ }^{\star}$ Mean cost saving.

†Median cost saving. 
Table 4 Diagnostic tests used in the chest pain observation unit protocols

\begin{tabular}{lllll}
\hline First author & $\begin{array}{l}\text { ST } \\
\text { monitor }\end{array}$ & Cardiac enzymes & $\begin{array}{l}\text { Exercise } \\
\text { stress test }\end{array}$ & Others \\
\hline Farkouh $^{17}$ & Yes & CK-MB & Yes & Nuclear or ECHO stress test $\dagger$ \\
Roberts $^{18}$ & No & CK-MB & Yes & Nil \\
Gomez $^{19}$ & Yes & CK, CK-MB & Yes & ECHO, dobutamine stress ECHO \\
Gaspoz $^{20}$ & No & CK-MB & Yes & Nil \\
Kerns $^{21}$ & No & Nil & Yes & Nil \\
Gibler $^{23}$ & Yes & CK-MB & Yes & ECHO \\
Kirk $^{24}$ & No & Nil & Yes & Nil \\
Mikhail $^{26}$ & Yes & CK, CK-MB, myoglobin & Yes & Nuclear or ECHO stress test $†$ \\
De Leon $^{27}$ & No & CK, LDH, CK-B & No & Nil \\
Hoekstra $^{29}$ & Yes & CK, CK-MB & Yes & ECHO \\
Stomel $^{28}$ & No & CK-MB & No & Stress ECHO \\
& & & &
\end{tabular}

* Selected patients only.

†If unable to exercise. $\mathrm{CK}=$ creatine kinase; $\mathrm{CK}-\mathrm{MB}=$ creatine kinase $\mathrm{MB}$ isoenzyme; $\mathrm{ECHO}=$ echocardiogram; $\mathrm{LDH}=$ lactate dehydrogenase.

Nine studies comparing costs of a CPOU to routine care were found, ${ }^{18-21} 26^{28-31}$ two of which were only in abstract form. ${ }^{30}{ }^{31}$ Two of the studies consisted of two separate comparisons so there were a total of 11 comparisons to review. ${ }^{19}{ }^{29}$ These are outlined in table 3. One other study was found that compared resource use but no costs. ${ }^{32}$ Data from this institution, including costs, has been published elsewhere. ${ }^{30}$

Table 4 outlines the diagnostic tests used in each of the CPOU protocols described in the literature.

\section{Discussion}

The effectiveness of the CPOU has been investigated by five comparative studies. ${ }^{17-21}$ Despite differences in inclusion criteria, method of allocation to treatment, and follow up there is broad similarity in outcomes. No significant difference in any objective outcome measure has been demonstrated. The main threat to the validity of this conclusion is the small number of deaths, AMI, and complications in these low risk subjects. A larger trial might be needed to detect a small difference in these outcomes, but it appears that the CPOU does not markedly affect hard outcome measures.

More subjective outcomes should be interpreted with caution in view of the inability of researchers to institute blinding. The only significant difference in outcome detected was an increase in diagnostic certainty after CPOU assessment. ${ }^{18}$ Two studies recorded a non-significant trend towards higher reattendance rates among CPOU patients (Farkouh et $a l^{17}: 8.0 \% \quad v \quad 4.2 \%$ and Roberts et $a l^{18}$ : $6.1 \%$ v $4.5 \%$ ). These are measures of processes of care and their value to the patient is debatable.

A further study by Rydman et al reported improved patient satisfaction among patients referred to a CPOU when compared with routine care, ${ }^{22}$ but this may be an example of patient preference bias. ${ }^{33}$ Being a randomised controlled trial of a new intervention, patients who have a preference for CPOU care can only obtain it by entering the trial and risking disappointment if they are randomised to the control. While those with a preference for routine care can be sure to obtain their preference by refusing consent. Unless patients have no preferences recruitment will be biased towards those who prefer CPOU care.
It should be noted that all the aforementioned studies compare CPOU patients with those admitted. A more appropriate comparison would also include patients discharged after initial emergency department assessment so as to report the proportion of AMIs discharged. Such a study, particularly if randomised, would present significant logistic and ethical problems but must be considered the only way of providing definitive proof of the relative effectiveness of the CPOU.

Descriptive and comparative studies have now reported large numbers of patients receiving CPOU assessment. ${ }^{17-21}{ }^{23-28}$ Follow up by telephone or mail is reasonably comprehensive and, supported by searches of death registries, is adequate to ensure that significant symptomatic pathology is not being missed. Death and complication rates do not exceed those expected for the study population and it is reasonable to conclude that the CPOU is a safe management strategy for low risk patients. Protocols consisting of continuous ST monitoring, creatine kinase $\mathrm{MB}$ isoenzyme measurement, and exercise stress testing seem to be the standard practice. Most result in discharge of around $80 \%$ of CPOU patients. The low discharge rates seen in the studies by Farkouh et $a l^{17}$ and Roberts et $a l^{18}$ probably occur because these protocols stipulate admission of those with inconclusive exercise testing.

It is tempting to compare the results of CPOU follow up with the previously reported rates of missed AMI. ${ }^{12}$ Indeed, this has been done to conclude that the CPOU reduces inadvertent discharge of AMI. ${ }^{25}$ This conclusion should be resisted for two important reasons. Firstly, none of the studies of CPOUs report testing for missed AMI with clinical, ECG, and enzyme assessment at 48-72 hours after discharge. Without such rigorous follow up it is impossible to tell if an equivalent number of AMIs are missed. Secondly, estimates of missed AMI rates predate many changes in emergency management of chest pain that may have improved or increased the caution with which patients with chest pain are managed. The use of historical controls is recognised to exaggerate the effects of new interventions, ${ }^{34}{ }^{35}$ and any conclusion of benefit based on such a comparison should be viewed with scepticism. Though it is reasonable to conclude that the CPOU offers a safe alternative to hospital admission, there is no convincing evidence of improved outcome.

Even if the CPOU is no more effective than routine care in ensuring safe discharge of patients with chest pain, surely the evidence of cost saving provides a compelling reason to introduce this form of care to the UK? Before this can be accepted the validity of cost estimates and their applicability to the UK must be reviewed.

Economic evaluations are subject to many of the same threats to validity as clinical trials. ${ }^{16}$ The value of concealed, random allocation in preventing known and unknown confounders being over-represented in one or other group is such that for clinical trials and economic evaluations it is considered to be the gold standard. ${ }^{14}$ 
Non-random allocation may cause bias if subjects with a different prognosis are systematically allocated to one group. ${ }^{36} 37$ The CPOU has been investigated by both randomised ${ }^{18} 19$ and non-randomised methods ${ }^{20} 26^{28-31}$ and it is noticeable that cost savings are less impressive when a randomised method is used (see table 3).

Randomised trials may also be subject to bias. Subjects may be selected for inclusion in a trial on the basis that they are deemed "suitable" for the new intervention. Management decisions may be influenced by awareness that the CPOU patient is under investigation. Patients may refuse consent if they are adverse to any risk associated with discharge and express a preference for more investigation or a longer hospital stay. If only hospital costs are recorded then significant costs incurred as outpatients may be missed. All such factors will tend to exaggerate the potential for the CPOU to reduce costs and must be considered when reviewing claims of cost effectiveness.

The potential for cost saving will also depend upon the proportion of patients normally discharged directly from the emergency department. ${ }^{25}$ Most estimates of cost minimisation (even from randomised controlled trials) compare CPOU patients with those admitted..$^{19^{12} 26^{28-31}}$ If the presence of a CPOU leads to enrolment of patients who would normally be discharged, then this comparison will no longer be valid and cost savings reduced. It is noticeable from table 3 that the only trial with a control group that included those discharged directly from the emergency department had a relatively low cost saving per patient. ${ }^{20}$

The costing of all these trials was limited. Only hospital costs were included and only two studies looked beyond inpatient costs. ${ }^{19} 20$ If, by facilitating early discharge, a CPOU simply moves investigations from an inpatient to an outpatient setting, then cost savings detected by analysis of inpatient costs only will be an overestimate. The use of patient charges to estimate costs may also introduce inaccuracy. Cross subsidising may mean that charges are a poor reflection of costs.

The application of trial findings to local circumstances must be considered. Protocols for the CPOU are usually well defined and can be transferred from one location to another. However, routine practice for hospital admission may vary greatly. It is important that local practice for patients admitted with chest pain is similar to that of the control population in a trial if cost savings are to be reproduced. For example, some studies report rates of inpatient coronary catheterisation for controls of $20 \%-25 \% .{ }^{19}{ }^{29}$ Such high cost comparisons are unlikely to be found in the UK. The extent to which subsequent costs should be included in the analysis is a matter of debate and depends upon the economic viewpoint. From the A\&E viewpoint it may be reasonable to only consider costs incurred in detecting or ruling out acute disease. Given the present low rate of interventional cardiology in the UK, the introduction of a CPOU that increases the detec- tion of cases of coronary artery disease may result in more cardiology referrals and therefore greater costs. Whether this is appropriate or not requires a subjective judgment.

This review takes a critical look at the arguments in favour of the CPOU. We can conclude that CPOU care is safe and that resource use is controlled and well defined. Uncertainty remains regarding whether the CPOU can improve patient outcomes and whether cost savings can be reproduced in the UK. It should be noted that much of this uncertainty relates to a lack of comparative data on present practice in the UK. It would be perverse to use this uncertainty to conclude that there is insufficient evidence to establish CPOUs in the UK.

The problem of chest pain management in the $\mathrm{A} \& \mathrm{E}$ department is unlikely to diminish in the future. The potential benefits of early thrombolysis mean that patients will be encouraged to attend the A\&E department early if they experience acute chest pain. We need to have strategies in place to manage these patients if the ECG is non-diagnostic. Bed availability for emergency admissions is unlikely to increase to meet this demand. Meanwhile the potential for litigation if patients with AMI are discharged is likely to increase. All this suggests that we cannot afford to be complacent about our management of patients with chest pain. The evidence base for the CPOU may have its limitations but we have little evidence to support our present approach.

\section{Conclusion}

The CPOU offers a safe alternative to routine hospital admission that may be cheaper and more effective. The potential for cost saving depends upon the proportion of patients attending the $\mathrm{A} \& \mathrm{E}$ department who are subsequently admitted, the typical resource use of those admitted, the proportion of those admitted who would be suitable for care on a CPOU, and the ability of the A\&E department to support CPOU services in an efficient manner. Further evidence is essential to determine whether this promising new approach can be applied in the UK.

I thank Francis Morris, Jim Wardrope, and the anonymous reviewers for their comments and suggestions relating to this article.

Conflict of interest: the author has been involved in establishing a pilot chest pain observation unit at the Northern General Hospital in Sheffield.

Funding: none.

1 Selker HP, Griffith J, Dorsey F, et al. How do physicians dmit when the coronary care unit is full? $7 A M A$ 1987;257:1181-5

2 Lee TH, Ting HH, Shammash JB, et al. Long-term survival of emergency department patients with acute chest pain. Am $\mathcal{F}$ Cardiol 1992;69:145-51.

3 Nichol G, Walls R, Goldman L, et al. A critical pathway for management of patients with acute chest pain who are at ow risk for myocardial ischemia: recommendations and potential impact. Ann Intern Med 1997;127:996-1005.

4 Zalenski RJ, Rydman RJ, McCarren M, et al. Feasability of a rapid diagnostic protocol for an emergency department chest pain unit. Ann Emerg Med 1997;29:99-108.

5 Emerson PA, Russell NJ, Wyatt J, et al. An audit of doctor's management of patients with chest pain in the accident and management of patients with chest pain in the acciden

6 Fothergill NJ, Hunt MT, Touquet R. Audit of patients with chest pain presenting to an accident and emergency de:155-60. 
7 McCallion WA, Templeton PA, McKinney LA, et al. Missed myocardial ischaemia in the accident and emergency department: ECG a need for audit? Arch Emerg Med 1991; 8:102-7.

8 Gibler WB. Chest pain units: do they make sense now? Ann Emerg Med 1997;29:168-171.

9 Hlatky MA. Evaluation of chest pain in the emergency department. N Engl F Med 1997;337:1687-8.

10 Zalenski RJ, Rydman RJ, Ting S, et al. A national survey of emergency department chest pain centres in the United States. Am 7 Cardiol 1998;81:1305-9.

11 Stahmer SA. Recent advances. Accident and emergency medicine. BMF 1998;316:1071-4.

12 El Gaylani N, Weston CMF, Shandall A, et al. Experience of a rapid access acute chest pain clinic. Ir Med $\mathcal{F}$ 1992;90:139-40.

13 Newby DE, Fox KA, Flint LL, et al. A "same day" direct-access chest pain clinic: improved management and direct-access chest pain clinic: improved manager
reduced hospitalization. $Q \mathcal{F}$ Med 1998;91:333-7.

14 Sackett DL, Haynes RB, Guyatt GH, et al. Deciding on the best therapy. Clinical epidemiology. A basic science for clinical medicine. Boston: Little, Brown, 1991: 187-248

15 Altman DG. Better reporting of randomised controlled Altman DG. Better reporting of randomised controlled

16 Drummond MF, Jefferson TO. Guidelines for authors and peer reviewers of economic submissions to the BMJ. $B M \mathcal{F}$ 1996;313:275-83.

17 Farkouh ME, Smars PA, Reeder GS, et al. A clinical trial of a chest pain observation unit for patients with unstable angina. N Engl f Med 1998;339:1882-8.

18 Roberts RR, Zalenski RJ, Mensah EK, et al. Costs of an emergency department-based accelerated diagnostic protocol vs hospitalization in patients with chest pain. A randomized controlled trial. $\mathcal{F} A M A$ 1997;278:1670-6.

19 Gomez MA, Anderson JL, Karagounis LA, et al. An emergency department-based protocol for rapidly ruling out myocardial ischemia reduces hospital time and expense: results of a randomized study (ROMIO). $7 \mathrm{Am}$ expense: results of a rando $1996 ; 28: 25-33$.

20 Gaspoz J, Lee TH, Weinstein MC, et al. Cost-effectiveness of a new short-stay unit to "rule out" acute myocardial infof a new short-stay unit to "rule out" acute myocardial inf-
arction in low risk patients. F Am Coll Cardiol 1994;24: arction in

21 Kerns JR, Shaub TF, Fontanarosa PB. Emergency cardiac stress testing in the evaluation of emergency department patients with atypical chest pain. Ann Emerg Med 1993;22 $794-8$

22 Rydman RJ, Zalenski RJ, Roberts RR, et al. Patient satisfaction with an emergency department chest pain observation unit. Ann Emerg Med 1997;29:109-15.
23 Gibler WB, Runyon JP, Levy RC, et al. A rapid diagnostic and treatment center for patients with chest pain in the mergency department. Ann Emerg Med 1995;25:1-8.

24 Kirk JD, Turnipseed S, Lewis RL, et al. Evaluation of chest pain in low-risk patients presenting to the emergency department: the role of immediate exercise testing. Ann Emerg Med 1998;32:1-7.

25 Graff LG, Dallara J, Ross MA, et al. Impact on the care of the emergency department chest pain patient from the chest pain evaluation registry (CHEPER) study. Am f Cardiol 1997;80:563-8.

26 Mikhail MG, Smith FA, Gray M, et al. Cost-effectiveness of mandatory stress testing in chest pain center patients. Ann Emerg Med 1997;29:88-98.

27 De Leon AC, Farmer CA, King G, et al. Chest pain evaluation unit: a cost-effective approach for ruling out acute myocardial infarction. South Med $\mathcal{F} 1989 ; 82: 1083-9$.

28 Stomel R, Grant R, Eagle KA. Lessons learned from a community hospital chest pain center. Am $\mathcal{f}$ Cardiol 1999;83: munity

29 Hoekstra JW, Gibler WB, Levy RC, et al. Emergencydepartment diagnosis of acute myocardial infarction and ischemia: a cost analysis of two diagnostic protocols. Acad

30 Rodriguez S, Cowfer JP, Lyston DJ, et al. Clinical efficacy and cost-effectiveness of rapid emergency department rule out myocardial infarction and noninvasive cardiac evaluation in patients with acute chest pain (abstract). $F \mathrm{Am}$ Coll Cardiol 1994;23(suppl):284A

31 Sayre MR, Bender AL, Dey CC, et al. Evaluating chest pain patients in an emergency department rapid diagnostic and treatment center is cost-effective. Acad Emerg Med 1994;1: A45.

32 Doherty R, Barish RA, Groleau G. The chest pain evaluation center at the University of Maryland Medical Center. Md Med f 1994;43:1047-52.

33 Brewin CR, Bradley C. Patient preferences and randomised controlled trials. BMF 1989;299:313-15.

34 Miller JN, Colditz GA, Mosteller F. How study design affects outcomes in comparisons of therapy. II: Surgical. affects outcomes in compar
Stat Med $1989 ; 8: 455-66$.

35 Sacks H, Chalmers TC, Smith H. Randomized versus historical controls for clinical trials. Am $\mathcal{F}$ Med 1982;72: 233-40.

36 Kunz R, Oxman AD. The unpredictability paradox: review of empirical comparisons of randomised and nonrandomised clinical trials. BMF 1999;317:1185-90.

37 Brennan P, Croft P. Interpreting the results of observational research: chance is not such a fine thing. BMF 1994;309: 727-30.

Applications are invited for the post of:

\section{EDITOR}

\section{Journal of Accident \& Emergency Medicine}

Specialists in emergency medicine are invited to apply for the post of Editor. Please send a letter of application, a curriculum vitae, and a short statement about the strengths and weaknesses of $\mathcal{F A E M}$, and your proposed editorial policy. Full editorial support will be provided and it is envisaged that the editor will need to devote about half a day a week to the journal. We seek applicants world wide from individuals or from two or more candidates wishing to act as co-Editors.

Closing date is 16 February 2000. Interviews will be held in March 2000 to enable the successful candidate to take up the post during the year.

Details of the post can be discussed with Alex Williamson, to whom applications should be sent. A job description is available on request.

Mrs Alex Williamson, BMJ Publishing Group, BMA House, Tavistock Square, London WC1H 9JR. Tel: +44 171383 6169; Fax: +44 171383 6668; Email: awilliamson@bmigroup.com 